\title{
Eliciting Persian Requests: DCT and Role Play Data
}

\author{
Abbass Eslami Rasekh \\ English Department, Faculty of Foreign Languages, University of Isfahan, \\ Isfahan 81746-7344, Iran \\ E-mail: Abbasseslamirasekh@yahoo.com \\ Ehsan Alijanian (Corresponding author) \\ University of Isfahan \\ E-mail: Ehsanalijanian@gmail.com
}

Received: May 20, 2012

doi:10.5430/wje.v2n3p80
Accepted: June 1, 2012

Published: June 15, 2012

URL: http://dx.doi.org/10.5430/wje.v2n3p80

\begin{abstract}
The validity of speech act data taken from different kinds of elicitation instruments has been widely discussed in interlangauge and cross cultural pragmatics literature. In this study an attempt is made to evaluate and investigate data taken from two of the most popular speech act instruments namely, written DCT and closed role play. The responses of forty Iranian university students in their native language (Persian) were investigated across the speech act of request. The distinguishing feature of the study is using the same participants for the two methods; in this way we can have an account of intra-participant variations. The social status and distance of the participants were both equal. Differences were found in the length and content of the responses. Respondents to role play tended to have longer responses and it was mainly because of the longer and higher number of alerters and supportive moves used in the role play. In the written data we witnessed more direct strategies used in the request Head Acts. Likewise, modification devices used in the oral data had a softer tone and in terms of request perspective the oral data provided more impersonal responses while the requests in the written data were more hearer-oriented. Overall, it seems that the data gathered through role play is more natural than DCT. Finally it is discussed that the choice of data gathering instrument in pragmatics research is to a large extent dependent on the goals of the researcher and research questions.
\end{abstract}

Keywords: Speech act instrument, Intra-participant variation, Social status, Social distance

\section{Introduction}

Researchers in the field of pragmatic studies have emphasized the importance of methodological issues (Kasper \& Dahl, 1991; Cohen, 1996). The choice of the instrument will determine the reliability and accuracy of the data that represent the authentic performance of the language related behavior. It has been mentioned that discourse completion task (DCT) and role play are two primary elicitation measures used in speech act and cross cultural pragmatic studies (kasper\& Dahl, 1991; Chaudron, 2005). These two tasks are especially used in EFL settings since it is difficult to collect sufficient naturally occurring data in these settings and also because of the problem of controlling the pragmatic parameters in naturally-occuring conversation. The validity of these two tasks has become especially important for researchers. No matter what else we do, we must remember that if data are inadequate, there is always the danger that the theory and conclusion drawn from them could be unreliable and misleading (Wolfsen, 1986).

DCTs put forth a situation in which respondents are expected to produce what they deem to be appropriate for that particular situation. DCTs have been widely used in speech act studies because of the several advantages. They let the researcher collect a large amount of data quickly (Yamashita, 1996). Also they make it possible to control situational variables such as social status, age, gender, and L2 proficiency (Kasper, 2000). Another advantage of DCTs is that there is no need for transcription which can cause easier comparison of the data elicited from different respondents (Chaudron, 2005). DCTs can also be administered to a large number of respondents and therefore making it possible to compare the responses of native and nonnative speakers across different cultures (Blum-Kulka et al., 1989a).

But DCTs are problematic when it comes to validity. (Golato, 2003). DCTs are decontextualized and respondents do not face the real life situations so the data represents what people think they would say not what they actually say (Aston, 2004). 
Another shortcoming related to validity is that respondents`oral performance is intended to be measured through the written mode (Kasper \& Dahl, 1991). Completers of DCTs may also think of the written task as some formal activity and as a result may apply more formal language (Beebe \& Cummings, 1996).

In role play participants are asked to take a particular role requiring the completion of a speech act. Role plays have been divided into two major categories. In case, the participants are given freedom to interact with the interlocutor we have open role plays but when the respondent is given few or no opportunities to interact we have closed role plays. Open role plays are more time consuming to conduct since they take more conversational turns. In closed role plays it is easier to control the procedure. Role play has been used widely for deriving behaviors of native and nonnative speakers in a variety of speech acts such as apologies, requests, refusals, compliments, and gratitude since it solves some of the shortcomings of DCTs. Data gathered through role plays is in the oral mode rather than written mode and this makes the data closer to what and as much as what respondents would say in real situations (Houck \&Gass, 1996). Also features of natural discourse such as turn-taking, false starts, and hesitation reflect natural speeches in role plays (Kasper \& Dahl, 1991). Nevertheless, the data gathered through role plays has come under question. In role plays, participants are not involved in naturally occurring interactions and are just playing the roles in specific situations and this causes the responses to be uncertain reflections of real language behavior (Kasper, 2000).

A number of studies have juxtaposed the data taken from of DCTs and role plays. Reintell and Mitchel (1989) compared closed role play and DCT for eliciting requests and apologies from native speakers and non-native speakers in terms of response length and range of linguistic strategies. They witnessed that in role plays non native speaker respondents produced much longer responses than DCTs. Reportedly, this length difference was due to non-native speakers` longer supportive moves, repetitions, and hesitations. Also the oral data tended to be more direct than the written mode. Beebe et al., (1996) and Wolfson et al., (1989) found a number of differences between data collected by DCT and role play In terms of actual wording used in real interpersonal interaction, the length of response or the number of turns it takes to fulfill the function, the number of repetitions and elaborations that occur, and the depth of emotion that in turn qualitatively affects the tone, content, and the form of linguistic performance.

It can be mentioned that the previous research on comparing these two tasks has a number of limitations. First, the data gathered is not that much comparable because they were elicited from different participants with diverse backgrounds in mother tongue, age, education, and cultural background as these variables may affect the result (Yamashita, 1996). Using the same participants for both methods is important when checking the validity and reliability of these instruments as evaluation measures (Alderson et al., 1995). Second, situations used for DCTs and role plays were often not appropriate for all types of respondents. In many of these studies students were put in situations that seem inappropriate. For example in Hudson et al. (1995) study students have to take the role of a person who holds a lease from the bank or an individual playing the role of a manager hiring employees.

The study tries to compare participants`responses (native language) elicited from DCTs and role plays with regards to length and content; in doing so the same respondents have been used. The participants are native speakers of Persian. In interlangauge and cross cultural studies usually the students performance in their native language is compared to their performance in the second language or performance of the native speakers of language A is compared to performance of native speakers of language B or sometimes the answers of native speakers of a language are evaluated against responses of speakers of a second language. With this in mind, it seemed necessary for the researchers to investigate whether performance of native speakers of Persian measured by the two mentioned instruments are the same.

\section{Methodology}

\subsection{Participants}

Forty university male students majoring in Mechanical engineering were chosen for this study. They were between the age ranges of 18 to 22 .

\subsection{Instruments}

Our data were gathered by means of role play and DCT. Eight request situations were devised for both the role play and DCT. On DCT, respondents were provided with given situations which required them to write down responses they believed are most appropriate for that context. We made use of closed role plays in which participants are not allowed to interact freely with the interlocutor. Respondents were asked to take the assumed role and pretend that their responses are part of longer conversation therefore some degree of unnaturalness was imposed on our participants.

All the participants in our study were university students and in this way it was made possible to control their educational background and age. The roles respondents played were as natural as possible since this role was part of their life. Participants would not perform a role which was different from them e.g., a boss, a pilot, or a professor. 
Trosborg (1995) believes that imposing roles which respondents are not familiar with would impact the naturalness of the performance. In our scenarios both the social status and the social distance was equal; the situations for the study were those that would occur between classmates or friends in their university setting or daily life.

\subsection{Procedure}

The forty participants were first given the handout in which the situations were explained; they were given enough time to study the situations. Then two by two they were taken to another room to perform the role plays and were audio-recorded. After they finished the eight situations, they were released and the next pair started the procedure. So here we had twenty requests.

Ten days after the role plays, the twenty students who had made requests were asked to complete a DCT. The completers were provided with exactly the same situations they were exposed to for role play. Respondents had enough time and space to complete the DCT. The idea for administering the role play before the DCT was to give spontaneity and to reduce the practice effect of the role play.

\subsection{Data Analysis}

The data was assessed with regards to length and content of the responses elicited from role plays and DCTs. Regarding role plays, all the conversations were transcribed. The parts which were not relevant to the speech act of request were omitted. For instance participants`statement after the request was conceived by the interlocutor was not analyzed. To examine the length of requests made, repetition or hesitation was counted as one word and interjections were not counted.

To investigate requests, Cross Cultural Study of Speech Act Realization Patterns (CCASRP) coding scheme was applied (see the Appendix of Blum-Kulka et al., 1989a). This design indicates that requests are comprised of the following parts: Head Act (e.g., 'could you do the cleaning up?'), alerter (e.g.,' excuse me', 'Joe'), preposed supportive moves (e.g., 'I really need a favor'), postposed supportive move (e.g., 'I promise I'll have it ready by tomorrow'). In this categorizations, nine strategies have been considered for Head Acts based on the degree of directness. The strategies are:

1- Mood derivable: e.g., Clean the table.

2- Explicit performative: e.g., I am asking you to clean the table.

3- Hedged performative: e.g., I have to ask you to clean the table.

4- Locution derivable: e.g., You have to clean the table.

5- Want statement: e.g., I want the table cleaned.

6- Suggestory formula: e.g., How about cleaning the table?

7- Prepatory: e.g., Could you clan the table?

8- Strong hint: e.g., The table is dirty.

9- Mild hint: e.g., I am exhausted to clean the table.

Also the Head Act can be modified by devices such as lexical/phrasal downgraders (marker please, consultive devices, downtoners, understaters/hedges, subjectivisers, cajolers, appealers) or syntactic downgraders (conditional structures, conditional clause, tense, aspect, interrogative, negation of prepatory condition). The preposed and postposed supportive moves can also be modified by devices such as grounder, disarmer, prepator, getting a precommitment, promise, imposition minimiser, apology, and discourse organization move.

Request perspective was another variable which was investigated in the two types of data. Requests usually include reference to the requester, the recipient of the request, and/or the action to be performed. The speaker can manipulate requests by choosing from a variety of perspectives (Blum-Kulka et al., 1989b) in making requests: Hearer-oriented (emphasis on the role of the hearer), Speaker-oriented (emphasis on the speaker's role as the requester), Speaker- and hearer-oriented (inclusive strategy), and Impersonal.

Therefore, the students` responses to DCT (written) and role play (oral) were compared in terms of length of alerters, supportive moves, Head Acts, and choice of perspective.

\section{Result and Discussion}

\subsection{Response Length}

Our analyses show a significant difference between the written and oral data in terms of length of responses. As Table 1 indicates the role play responses are significantly longer than DCT answers although they are produced by the same completers. 
This mean difference can be explained by the nature of role plays which cause more hesitation, inversion, and repetition. Another reason for this length difference was the use of more and longer alerters and supportive moves used by role play participants. As an example in oral data the participants used alerters such as 'Bebakhshid' 'Excuse me', 'Ozrmikhamghorban' 'Excuse me sir' much more than the written data. This finding confirms (Blum-Kulka et al., 1989b) who highlighted the importance of alerters in conversations. Also the study by Yuan (2001) found a significant difference between the length of responses in the oral and written data but since here the same participants were used in both mediums our result is more solid. Based on the above, we can state that role play generates more natural data than DCT.

\subsection{Alerters and Supportive Moves}

As Table 2 indicates there is a significant difference between frequency of alerters in the oral and written data. In the role play we have a higher number of both alerters and supportive moves than DCT. These alerters are used in role play to draw the attention of the audience but this does not happen in the written data. Regarding supportive moves we can claim that since the directions (prompts) in the DCT cannot instigate the actual situation, respondents use shorter or no supportive moves. It seems that role play is more effective in eliciting what completers would do in real interaction.

<Table 2 about here>

In terms of type of alerters, completers used more types of alerters in role play than in DCT. In Role play four types of alerters were used while in DCT two types were elicited. The most frequent alerter used in both DCT and role play was 'bebakhshid, Ozrmikham', 'Excuse me’ (Table 3).

\section{$<$ Tables3 \& 4 about here>}

As table 4 indicates for supportive moves, Role play data show six different devices but in DCT responses only four supportive moves were identified. Grounder was the most frequent supportive move in both DCT and role play followed by disarmer, prepator, and imposition minimizer. Only in role play apology and discourse organization move were used. This shows that respondents can better feel the interactive nature of real situations in role plays.

\subsection{Head Act Strategies}

AS Table 5 shows some strategies are used more often in the oral data than the written data. What can be seen is that DCT responses include more direct strategies than those of the role play. Other studies (e.g., Blum-Kulka et al., 1989a ;Reintel\& Mitchel, 1989) that investigated the behavior of native English speakers also indicate the same pattern. It seems that there are factors in role plays which cause respondents to be less direct. This intra-participant variation indicates that different methods can elicit different data from the same respondents. So if different completers were measured through different methods, we could not have an account of these variations.

Table 5 indicates that strategies $4 \& 9$ were not used in either method. Strategy 2 was used in DCT but not in Role play and strategy 8 was used in role play but not in DCT. So Head act strategies are different in these two data elicitation methods.

<Table 5 about here>

\subsection{Internal Modifications Used in the Head Acts}

In general we encountered a high number of lexical and syntactic downgraders and the reason can be high level of proficiency of participants in their mother tongue. Takahashi and Beebe (1987) believe that participants with a good level of language proficiency elaborate speech act expressions. Lexical downgraders such as subjectivisers and appealers were not used in both written and oral data. The only syntactic downgrader not used in either DCT and role play was negation of prepatory condition. Table 6 indicates that Role play data reflect a higher number of downgraders than the DCT data (both syntactic and lexical). It indicates that in conversation respondents may have opted to apply a milder tone than in DCT.

<Table 6 about here>

\subsection{Request Perspective}

As Table 7 shows respondents to role play had the tendency to use more joint perspective and impersonal perspective while DCT completers` replies were more Hearer dominant. It indicates that in role play respondents are more cautious which can be considered as more natural.

$<$ Table 7 about here> 


\section{Conclusion}

Pragmatic competence is at the heart of current trends of language pedagogy. It is believed that failure in the mastery of speech act will cause communicative breakdown (Wolfson, 1989). Therefore, it seems necessary to have research in the issue of data collection method in order to confirm the validity and reliability of the instruments of data collection.

The study compares the data elicited from DCT and role play across the speech act of request. We used the same participants for both groups with the aim of having a controlled methodological comparison. In the data from the two instruments differences in terms of length and content of responses were found. It has been shown that completers provide longer responses in role play which is mostly because of the higher number of alerters and supportive moves used in the oral data. There was no difference between the varieties of strategies used in the two methods but in the written data more direct strategies were applied. Modification devices used in role play had a softer tone and finally the written data were more hearer-oriented while the oral data were more impersonal or collective referent in terms of perspective. Based on our findings we can state that role play is a more appropriate technique than DCT if we consider naturalness of speech. Turnbull (1997) outlines four criteria for good pragmatic elicitation technique; He argues that role play provides data which is representative of natural speech, it is efficient with regards to the extent of data it can gather, it gives room for researcher control, and finally it is ethical.

It should be mentioned that goals of the researcher and the research questions to a large extent determine the choice of speech act data elicitation instrument. For example, Although, DCT is not without its limitations, it can be used in investigation of a given speech act in a particular language in an early stage in order to delineate comprehension patterns. The findings of this study are grounded on the particular speech act of requesting by Persian speakers elicited from written DCT and closed role play in a testing situation while the social status and distance between respondents were equal. It is beyond denial that the use of different data collection techniques in different research issues needs empirical inquiry. However the conclusions drawn from this study should make researchers aware of not delving into the issue of pragmatic competence based on a single data collection instrument.

\section{References}

Alderson, J. C., Clapham. C.,\& Wall. D. (1995).Language test construction and evaluation. Cambridge: Cambridge University Press.

Beebe, L., \& Cummings, M. (1996). Natural speech data versus witten questionnaire data: How data collection method affects speech behavior. In S. Gass, \& J. Neu (Eds.), speech act across cultures: Challenges to communication in a second language (pp. 65-83). New York: Mouton de Gruyter.

Beebe, L., Takahashi, T., \&UIiss-Weltz.R. (1990).Pragmatic transfer in ESL refusals. In R. Scarcella, E. Andersen, \& S. Krashen (Eds.), Developing communicativecompetencies in a second language (pp. 55-73). New York: Newbury House.

Blum-Kulka, S., House, J., \& Kasper, G. (1989a).Cross-cultural pragmatics: Requests and apologies. Norwood, NJ: Ablex.

Blum-Kulka, S., House, J., \& Kasper, G. (1989b).Investigating cross-cultural pragmatics: An introductory overview. In S. Blum-Kulka, J. House, \& G. Kasper (Eds.), Cross-cultural pragmatics: Requests and apologies (pp. 1-34). Norwood, NJ: Ablex.

Chaudron, C. (2005). Data collection in SLA research. In C. J. Doughty, \& M. H. Long (Eds.), The handbook of second language acquisition (pp. 762-827). Blackwell publishing.

Cohen, A. D. (1996). Sppech acts. In S. L. Mckay, \& N. H. Hornberger (Eds.), Sociolinguistics and language teaching (pp. 51-84). Cambridge: Cambridge University Press.

Golato, A. (2003). Studying compliment reponses: A comparison of DCTs and recordings of naturally occurring talk. Applied Linguistics, (24), 90-120.http://dx.doi.org/10.1093/applin/24.1.90

Houck, N., \&Gass, S. M. (1996), Non-native refusals: A methodological perspective. In S.M. Gass, \& J. Neu (Eds.), Speech acts across cultures: Challenges to communication in a second language(pp. 45-64).Berlin: Mouton de Gruyter.

Hudson, T., Detmer, E., \& Brown, J. D. (1995).Developing prototypic measures of cross-cultural pragmatics. Technical Report, 7. Honolulu: University of Hawaii, Second Language Teaching and Curriculum Center, University of Hawai'I at Manoa. 
Kasper, G. (2000). Data collection in pragmatics research. In H. Spencery-Oatey (Ed.), Culturally speaking: Managing rapport through talk across cultures (pp. 316-341). London and New York: Continuum.

Kasper, G., \& Dahl, M. (1991).Research methods in interlanguage pragmatics.Studies in Second Language Acquisition, (13), 215-247.http://dx.doi.org/10.1017/S0272263100009955

Rintell, E.M., \& Mitchell, C.J. (1989). Studying requests and apologies: An inquiry into method. In S. Blum-Kulka, J. House, \& G. Kasper (Eds.), Cross-cultural pragmatics: Requests and apologies (pp. 248-272). Norwood. NJ: Ablex

Takahashi, T., \& Beebe, L. M. (1987).The development of pragmatic competence by Japanese learners of English.JALT Journal,(8),131-155.

Trosborg, A. (1995). Interlanguage pragmatics. Berlin: Mouton de Gruyter.http://dx.doi.org/10.1515/9783110885286

Turnbull, W. (1997).An appraisal of pragmatic elicitation techniques for the study of talk. Unpublished manuscript.Department of Psychology, Simon Fraser University, Burnaby, BC, Canada.

Wolfson, N. (1989). Perspectives: Sociolinguistics and TESOL. Cambridge, MA: Newbury House.

Wolfson, N., Marmor, T., \& Jones, S. (1989). Problems in the comparison of speech acts across cultures. In S. Blum-Kulka, J. House, \& G. Kasper (Eds.), Cross-culture pragmatics: Requests and apologies (pp. 248-294). Norwood, NJ: Albex.

Yamashita, S. (1996). Six measures of JSL pragmatics. (Technical Report \#14.) Manoa, HI: University of Hawaii Press.

Table 1. Mean response length of the participants

\begin{tabular}{|l|c|c|c|}
\hline Instrument & Mean & df & SD \\
\hline DCT & 130.55 & 19 & $0.65^{*}$ \\
\hline Role play & 144.44 & 19 & $0.52^{*}$ \\
\hline
\end{tabular}

$* \mathrm{P}<0.01$

Table 2. Mean frequency of alerters and supportive moves in participants`requests

\begin{tabular}{|l|c|c|c|}
\hline \multirow{2}{*}{ Formula } & \multicolumn{2}{|c|}{ Mean Frequency } & \multirow{2}{*}{$p$-value (Chi square) } \\
\cline { 2 - 3 } & DCT & Role play & \\
\hline Alerter & 15.2 & 24.4 & .00 \\
\hline Supportive move & 26.3 & 32.5 & .00 \\
\hline
\end{tabular}

Table 3. Mean number and percentage of alerters used in participants` responses

\begin{tabular}{|l|c|c|c|c|}
\hline \multirow{2}{*}{ Type } & \multicolumn{2}{|c|}{ DCT } & \multicolumn{2}{c|}{ Role play } \\
\cline { 2 - 5 } & Number & Percentage & Number & Percentage \\
\hline $\begin{array}{l}\text { Bebakhshid, Ozrmikham } \\
\text { Excuse me }\end{array}$ & 9 & $60 \%$ & $45 / 8 \%$ \\
\hline $\begin{array}{l}\text { Salam } \\
\text { Hello }\end{array}$ & 6 & $40 \%$ & 4 & $16 / 6 \%$ \\
\hline $\begin{array}{l}\text { Khastehnabashid } \\
\text { Cheer up }\end{array}$ & 0 & 0 & 5 & $20 / 8 \%$ \\
\hline First name (e.g., Ali) & 0 & 0 & 4 & $16 / 6$ \\
\hline
\end{tabular}


Table 4. Mean number and percentage of supportive moves used in participants`responses

\begin{tabular}{|l|c|c|c|c|}
\hline \multirow{2}{*}{ Type } & \multicolumn{2}{|c|}{ DCT } & \multicolumn{2}{c|}{ Role play } \\
\cline { 2 - 5 } & Number & Percentage & Number & Percentage \\
\hline Grounder & 10 & 38.4 & 8 & 25 \\
\hline Disarmer & 8 & 30.7 & 7 & 21.8 \\
\hline prepator & 5 & 19.2 & 5 & 15.6 \\
\hline Imposition minimizer & 3 & 11.5 & 5 & 15.6 \\
\hline Apology & 0 & 0 & 5 & 15.6 \\
\hline Discourse organization move & 0 & 0 & 2 & 6.2 \\
\hline
\end{tabular}

Table 5. Types of Strategies Used in the Head Acts

\begin{tabular}{|c|c|c|}
\hline Category & DCT & Role play \\
\hline 1. Mood derivable & $45 \%$ & $26 \%$ \\
\hline 2. Explicit performative & $15 \%$ & 0 \\
\hline 3. Heded performative & $15 \%$ & $9 \%$ \\
\hline 4. Locution derivable & 0 & 0 \\
\hline 5. Want statement & $8 \%$ & $19 \%$ \\
\hline 6. Suggestory formula & $15 \%$ & $11 \%$ \\
\hline 7. Preparatory & $12 \%$ & $21 \%$ \\
\hline 8. Strong hint & 0 & $14 \%$ \\
\hline 9. Mild hint & 0 & 0 \\
\hline
\end{tabular}

Table 6. Types of internal modifications used in the Head Acts

\begin{tabular}{|c|c|c|}
\hline Modifier & DCT & Role play \\
\hline $\begin{array}{l}\text { Lexical/phrasal downgraders } \\
\text { Marker 'please', consultive devices, downtoners, hedges, } \\
\text { cajoler,, }\end{array}$ & $35 \%$ & $65 \%$ \\
\hline $\begin{array}{l}\text { Syntactic downgraders } \\
\text { Conditional structures, conditional clauses, tense, aspect. } \\
\text { interogatives }\end{array}$ & $41 \%$ & $59 \%$ \\
\hline
\end{tabular}

Table 7. Choice of perspective by respondents in DCT and Role play

\begin{tabular}{|l|c|c|}
\hline Perspective & DCT & Role play \\
\hline Hearer dominance & $41 \%$ & $14 \%$ \\
\hline Speaker dominance & $31 \%$ & $27 \%$ \\
\hline Joint perspective & $18 \%$ & $39 \%$ \\
\hline Impersonal & $10 \%$ & $20 \%$ \\
\hline
\end{tabular}

